\title{
Quantitative trait loci for winter hardiness and other agronomic traits in the progeny of two amphiploid Festulolium hybrids (Festuca pratensis $\times$ Lolium perenne) backcrossed twice to tetraploid Lolium perenne
}

\author{
K. TAMURA ${ }^{1,2 *}$, Y. SANADA $^{2}$, K. TASE ${ }^{2 \dagger}$, Y. AKIYAMA $^{2}$, and A. KUBOTA ${ }^{3}$ \\ Institute of Livestock and Grassland Science, NARO, Nasu-shiobara, Tochigi 329-2793, Japan ${ }^{1}$ \\ Hokkaido Agricultural Research Center, NARO, Toyohira, Sapporo 062-8555, Japan ${ }^{2}$ \\ Tohoku Agricultural Research Center, NARO, Shimo-kuriyagawa, Morioka, Iwate 020-0198, Japan ${ }^{3}$
}

\begin{abstract}
To clarify the effects of the introduction of Festuca pratensis-derived genomic regions in a tetraploid Lolium perenne genomic background, we analyzed quantitative trait loci (QTLs) for winter hardiness and eight other agronomic traits using two mapping populations generated by sequential backcrosses of two different amphiploid $F$. pratensis $\times$ L. perenne hybrids to tetraploid L. perenne. We constructed two interspecific linkage maps: FLBC2A (143 DNA markers, $301.2 \mathrm{cM}$ total) and FLBC2C (126 markers, $256.2 \mathrm{cM}$ ), based on F. pratensis-derived alleles, with 72 markers in common. Interval mapping detected QTLs for seven traits in FLBC2A and for six traits in FLBC2C. In both populations, QTLs for winter hardiness with a positive effect of the F. pratensis allele were detected around common markers on linkage group (LG) 1 . In FLBC2A, other additional QTLs for winter hardiness with a positive effect of the $F$. pratensis allele were detected on LG4 and LG5, and one with a negative effect was detected on LG2. In both populations, a QTL for heading date was detected on LG7. Quantitative trait loci for vigor after planting and stubble width were detected on different LGs between populations. Quantitative trait loci for dry matter yield before winter, plant growth habit, inflorescence length, number of spikelets per inflorescence, and leaf width were detected in only one population. Population-dependent QTLs thought to be involved in intraspecific variation in addition to interspecific one. On the other hand, QTLs found in the two different populations could lead to the development of versatile markers for Festulolium breeding.
\end{abstract}

Additional key words: breeding, forage, inflorescences, interspecific linkage mapping, vigor.

\section{Introduction}

Festulolium refers to intergeneric hybrids generated naturally or artificially from crosses between species of the closely related genera Lolium and Festuca. Some hybrids are used for forage in temperate regions. As Festulolium hybrids often show complementary characteristics derived from both species, grass breeders aim to work out the optimal parental combinations to select progeny suitable for their breeding objectives (Ghesquière et al. 2010). In Hokkaido, northern Japan, $L$. perenne and $F$. pratensis cultivars are used mainly in pastures (Tamura et al. 2017). For more than a dozen years, a breeding program designed to combine the superior forage quality and palatability of $L$. perenne with the excellent winter hardiness of $F$. pratensis has been conducted in Hokkaido. In the Festulolium breeding of $F$. pratensis $\times$ L. perenne, amphiploid hybrids are generated from crosses of autotetraploids $F$. pratensis $(2 \mathrm{n}=4 \mathrm{x}=28)$ with $L$. perenne $(2 \mathrm{n}=4 \mathrm{x}=28)$, followed by several cycles of phenotyping and crossing. The amphiploid hybrids can be used for further backcrossing to parental species to generate introgression cultivars.

Information on quantitative trait loci (QTLs) for winter hardiness and other agronomic traits involved in phenotypic differences between Lolium and Festuca would be useful for Festulolium breeding, for example for the introgression of $F$. pratensis chromosome fragments carrying genes involved in winter hardiness into L. perenne. Previous studies revealed several Festuca-derived genomic regions involved in winter hardinessorfreezing tolerance when introgressed into the Lolium genome (Grønnerød et al. 2004, Kosmala et al. 2006, 2007, Humphreys et al. 2007,

Submitted 27 December 2019, last revision 9 April 2020, accepted 14 April 2020.

Abbreviations: AFLP - amplified fragment length polymorphism; GISH - genomic in situ hybridization; LG - linkage group; LOD logarithm of odds; SIM - simple interval mapping; QTL - quantitative trait locus.

Acknowledgements: We thank Toshiyuki Takeichi, Shuji Yanagiya, Machiko Fujimori, Yumi Hosokawa, Sanae Sudo, Hanae Nishizuka, and Satomi Shimada (Hokkaido Agricultural Research Center, NARO) for their technical assistance in the field and laboratory work.

$\dagger$ Present address: Japan Grassland Agriculture and Forage Seed Association, 406 Higashi-Nopporo, Ebetsu, Hokkaido 069-0822, Japan

* Corresponding author; e-mail: tamuken@affrc.go.jp 
Tamura et al. 2017) by analyzing superior genotypes selected from diploid introgression populations. To more comprehensively search for QTLs throughout the genome, a linkage mapping approach using progeny with segregation of target traits derived from parents with contrasting characteristics is needed. Linkage mapping was used to search for QTLs of winter hardiness throughout the genomes of $L$. perenne and F. pratensis (Yamada et al. 2004, Alm et al. 2011). QTLs found in the intraspecific mapping population are not necessarily available in the interspecific hybrids, and interspecific linkage mapping approach is appropriate to obtain valuable information for Festulolium breeding. As diploid Festuca $\times$ Lolium $\mathrm{F}_{1}$ hybrids are sterile (Ghesquière et al. 2010), fertile allotetraploid Festulolium hybrids should be used for interspecific linkage mapping. However, such approach has not been reported so far.

In theory, the first generation of the progeny of allotetraploid $F$. pratensis $\times$ L. perenne hybrids backcrossed to tetraploid $L$. perenne $\left(\mathrm{BC}_{1}\right)$ is expected to have three sets of $L$. perenne chromosomes and a single set of $F$. pratensis chromosomes considering preferential homologous chromosome pairing. However, some homoeologous pairing and recombination, as evidenced in several studies may result in a change in the proportion of chromosomes from parental genomes (Zwierzykowski et al. 2008, Majka et al. 2019, Kopecký et al. 2010). The second generation after backcrossing to tetraploid $L$. perenne $\left(\mathrm{BC}_{2}\right)$ is expected to display frequent formation of intergenomic multivalents during meiosis among the three $L$. perenne and one Festuca homoeologous chromosomes and subsequently, large extent of homoeologous recombinations (Kopecký et al. 2008), resulting in the segregation of F. pratensisderived loci in the tetraploid L. perenne background.

The aim of this study was to clarify the effect of the introduction of $F$. pratensis genomic regions in the tetraploid L. perenne background throughout the genome for future applications in Festulolium breeding. To find QTLs with high versatility in breeding, two different interspecific mapping populations generated from L. perenne $\times($ F. pratensis $\times$ L. perenne $)$ backcrosses were used for QTL analyses.

\section{Materials and methods}

Plants: We crossed two $\mathrm{F}_{2}$ amphiploid Festulolium genotypes, D5-2 and E6-2, derived from NARO breeding materials generated from multiple crosses among tetraploid $F$. pratensis $\times L$. perenne $\mathrm{F}_{1}$ hybrids that showed superior winter hardiness in Hokkaido (unpublished data), as male parents with tetraploid $L$. perenne cultivars as female parents: D5-2 with a genotype from cv. Chinita and E6-2 with a genotype from cv. Pokoro. From the respective $\mathrm{BC}_{1}$ populations, we selected genotypes 10EC12 and 13EP4, which showed moderate to high freezing tolerance (unpublished data) and crossed these with another genotypes from cvs. Chinita and Pokoro, respectively. The resultant $\mathrm{BC}_{2}$ populations FLBC2A $(n=164)$ and FLBC2C $(n=113)$ were used for the following QTL analyses.
Genomic in situ hybridization (GISH) of $\mathrm{BC}_{1}$ parents was performed according to Akiyama et al. (2010) with slight modifications. The GISH signals were detected by direct labeling of genomic DNA of $L$. perenne with fluorescein12-dUTP and of F. pratensis with Texas Red-5-dUTP (both stains from PerkinElmer, Billerica, MA, USA).

Phenotyping $\mathrm{BC}_{2}$ populations: Plants of the two $\mathrm{BC}_{2}$ populations (FLBC2A and $\mathrm{FLBC} 2 \mathrm{C}$ ) and their parents, raised in plastic nursery pots $(5 \times 5 \times 5 \mathrm{~cm})$ in a greenhouse, were transplanted to the field nursery of the Hokkaido Agricultural Research Center, NARO, Sapporo, Japan $\left(43^{\circ} 00^{\prime} \mathrm{N}, 141^{\circ} 25^{\prime} \mathrm{E}\right)$, on 22 August 2013. Three clones of each genotype were planted at a spacing of $80 \times 50 \mathrm{~cm}$ in a randomized block design with a basal fertilization at $4.2 \mathrm{~g}(\mathrm{~N}) \mathrm{m}^{-2}, 5.8 \mathrm{~g}\left(\mathrm{P}_{2} \mathrm{O}_{5}\right) \mathrm{m}^{-2}, 4.2 \mathrm{~g}\left(\mathrm{~K}_{2} \mathrm{O}\right) \mathrm{m}^{-2}$. After the snow had melted completely in each spring, inorganic fertilizer was applied at the same rate as basal fertilization. The first cut was made after the complete appearance of at least three inflorescences per clone in all plants, and the following cuts were made when the plant length reached $30-40 \mathrm{~cm}$, at a height of $7 \mathrm{~cm}$ above the ground, followed by the application of a fertilizer $\left[2.1 \mathrm{~g}(\mathrm{~N}) \mathrm{m}^{-2}\right.$, $1.6 \mathrm{~g}\left(\mathrm{P}_{2} \mathrm{O}_{5}\right) \mathrm{m}^{-2}, 2.1 \mathrm{~g}\left(\mathrm{~K}_{2} \mathrm{O}\right) \mathrm{m}^{-2}$. The plants were cut on 18 June, 15 July, 8 August, 17 September, and 15 October 2014; and on 26 June, 15 July, 28 August, 16 September, and 16 October 2015. Clones of all plants were phenotyped for nine agronomic traits : vigor index after planting, winter hardiness index (WHI), heading date, dry matter before winter, plant growth habit, inflorescence length, number of spikelets per inflorescence, leaf width, and stubble width (Table 1 Suppl.). If a clone died for any reason, heading date, growth habit, inflorescence length, number of spikelets, leaf width, and stubble width were not evaluated.

Genotyping and linkage mapping: We used three types of PCR-based markers: Lolium/Festuca intron-flanking markers (Table 2 Suppl.; Tamura et al., 2009, 2012) and EST-SSR markers of Festuca arundinacea (Table 3 Suppl., Saha et al. 2004) and L. perenne (Table 4 Suppl., Studer et al. 2010). For $\mathrm{BC}_{2}$ genotyping, from 412 markers, we selected markers associated with bands amplified in the two F. pratensis genotypes used as parents of the $\mathrm{F}_{1}$ hybrids and in the $\mathrm{BC}_{1}$ parents and not amplified in the L. perenne parents used for backcrossing. Genotyping was performed using agarose or acrylamide gel electrophoresis as described in Tamura et al. (2009, 2012, 2017). Amplifiedfragment-length polymorphism (AFLP) analysis using 12 combinations of primer sets were also performed on a GenomeLab GeXP genetic analysis system (Beckman Coulter, Brea, CA, USA) as described in its manual. Fragments amplified in the $F$. pratensis parents and $\mathrm{BC}_{1}$ parents and not amplified in the L. perenne parents were used as markers. Names of AFLP markers were based on the $3^{\prime}$ terminal sequences of the two primers used for the second amplification and the fragment length (shown 
in Fig. 3). $\mathrm{BC}_{1}$ parents were assumed to have one set of chromosomes from $F$. pratensis and three from $L$. perenne. To investigate the segregation of genetic loci derived from $F$. pratensis in the $\mathrm{BC}_{2}$ tetraploid population, we regarded the marker type showing the $F$. pratensis-derived allele as heterozygous and that not showing the $F$. pratensis-derived allele as homozygous for L. perenne. Linkage analysis was performed in JoinMap v. 4.0 software (Van Ooijen 2006). The population type was set as "BC1" to make a linkage map based on the segregation of $F$. pratensis-derived alleles. Marker order and genetic distance were calculated by a regression mapping algorithm with the Kosambi's mapping function with the logarithm of odds (LOD) threshold $=10$. Linkage group $(\mathrm{LG})$ and direction were based on the chromosome of the Lolium/Festuca intronflanking markers (Tamura et al. 2009) and GenomeZipper data (Byrne et al. 2015).

Analyses of QTLs was conducted by using the simple interval mapping (SIM) procedure in MapQTL 6 software (Van Ooijen 2009). Permutation tests (1000 iterations) were performed to determine LOD threshold, and loci with a LOD score above the threshold $(P<0.05)$ were considered as significant QTLs. When multiple peaks in SIM were detected in a single LG, multiple QTL mapping (MQM) was conducted using the nearest markers to the LOD peaks of QTLs in the SIM as co-factors. If all multiple QTLs in a single LG disappeared in MQM, they were regarded as a single QTL.
Statistical analysis: Broad-sense heritability:

$\left(h^{2}=\sigma_{\mathrm{g}}^{2} /\left(\sigma_{\mathrm{g}}^{2}+\sigma_{\mathrm{e}}^{2}\right) ; \sigma_{\mathrm{g}}^{2}\right.$ and $\sigma_{\mathrm{e}}^{2}$ are genetic and environmental variances, respectively) was estimated using the variance components calculated by analysis of variance (ANOVA). One-way ANOVA was conducted on genotypes having data of all three replications in each $\mathrm{BC}_{2}$ population. All statistical analyses were performed in $J M P$ 9 software (SAS Institute, Cary, NC, USA).

\section{Results}

Compared with the $L$. perenne parents, the $\mathrm{BC}_{1}$ parents used to generate the $\mathrm{BC}_{2}$ populations had superior vigor after planting, superior winter hardiness, more dry matter before winter, a longer inflorescence, more spikelets per inflorescence, wider leaves, and wider stubble (Table 5 Suppl.). In both $\mathrm{BC}_{2}$ populations, significant genotypic effects in all investigated traits $(P<0.001$, ANOVA) and wide variations in each trait (Table 5 Suppl. and Fig. 1) were confirmed. The broad-sense heritabilities of heading date were the highest among traits, 73 $83 \%$, whereas those of WHI were lower, 41 - $68 \%$ (Table 5 Suppl.). Correlations between 2014 and 2015 ranged from 0.59 (WHI in FLBC2C) to 0.86 (inflorescence length in $\mathrm{FLBC} 2 \mathrm{~A}$ ).

After winter, disease caused by snow molds, mainly Typhula ishikariensis, was detected in both populations. After the first winter, all clones survived in both populations, but after the second and third winters,

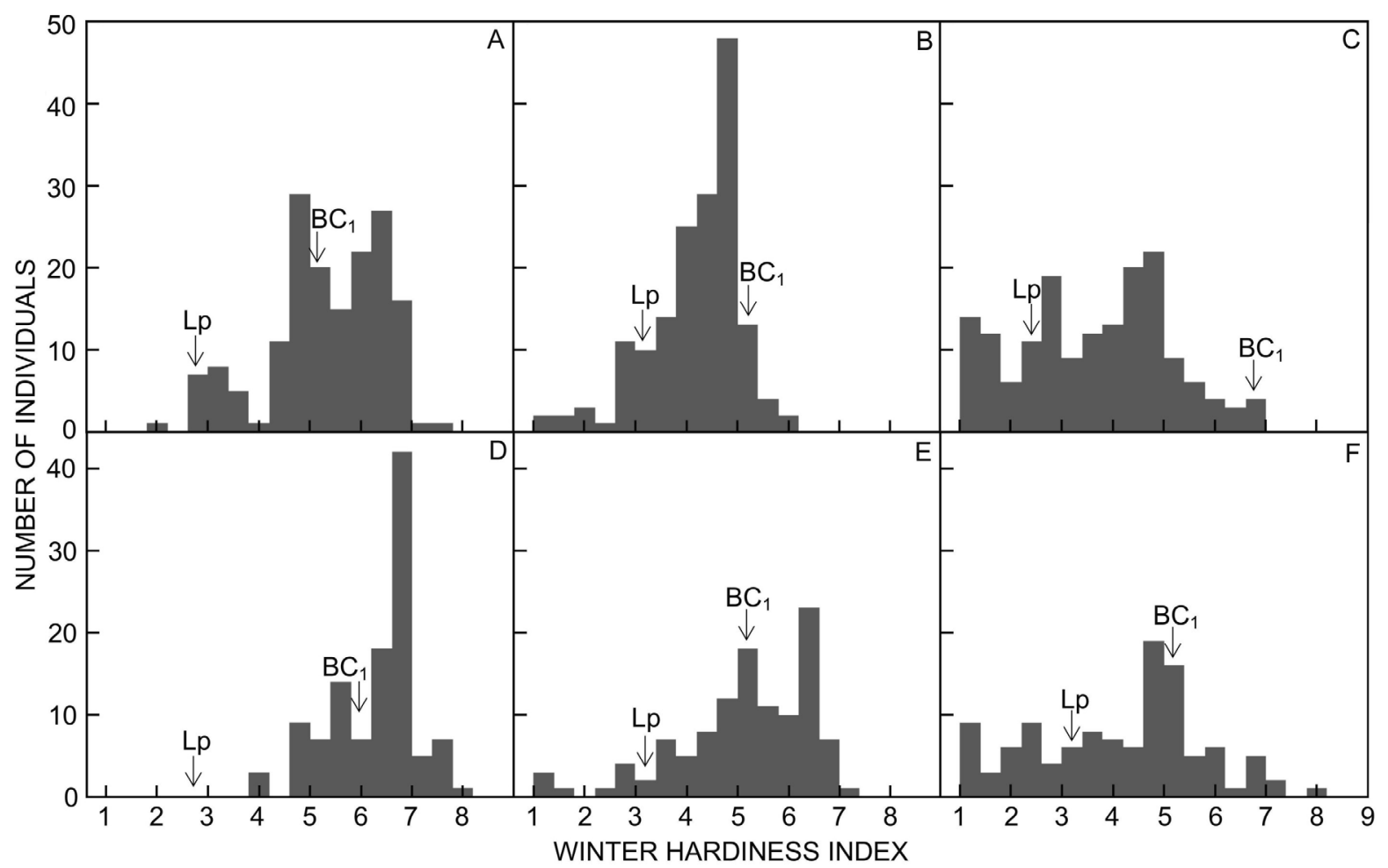

Fig. 1. Distribution of winter hardiness index $(1-9)$ of FLBC2A $(A, B, C)$ and FLBC2C $(D, E, F)$ populations in $2014(A, D), 2015(B, E)$, and $2016(C, F)$. Arrows show the bins, which include the parental values: Lp - Lolium perenne (female parent), $\mathrm{BC}_{1}-\mathrm{amphiploid}$ Festulolium (Festuca pratensis $\times$ L. perenne) $\mathrm{BC}_{1}$ (male parent). 

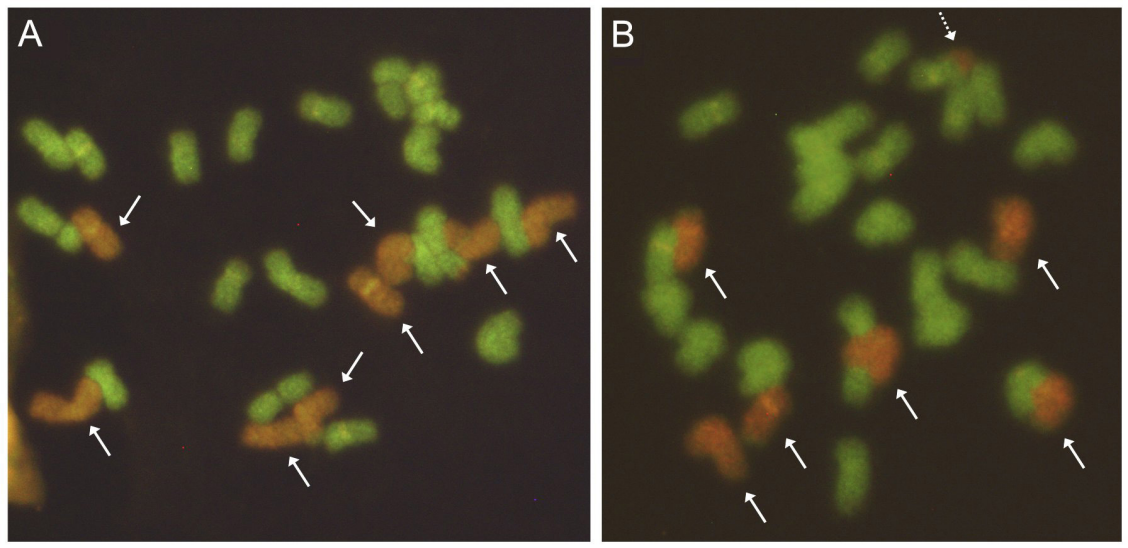

Fig. 2. Analysis of genomic in situ hybridization of $\mathrm{BC}_{1}$ plants used as male parents to generate $\mathrm{BC}_{2}$ mapping populations: $10 \mathrm{EC} 12$, male parent of FLBC2A $(A)$; 13EP4, male parent of FLBC2C $(B)$. Orange signals are derived from the Texas red-labeled Festuca probe, green signals are derived from the fluorescein-12-labeled Lolium probe. Arrows show F. pratensis-derived chromosomes, and a dotted arrow shows a F. pratensis-derived chromosome fragment recombined with L. perenne-derived one.

15 and 69 clones (3.0 and $14.0 \%$ ) in FLBC2A and 12 and 38 clones $(3.5$ and $11.2 \%$ ) in FLBC2C died; the WHI of these clones was evaluated as 1 . After three winters, most $\mathrm{BC}_{2}$ genotypes had a lower WHI than their $\mathrm{BC}_{1}$ parent (Fig. $1 C, F$ ). Means of WHI decreased and SD increased by year in both populations (Table 5 Suppl.). FLBC2A had a lower WHI in all years than FLBC2C $(P<0.01, t$-test $)$.

The GISH analysis, which can discriminate between Festuca- and Lolium-derived chromosomes, revealed that 10EC12, the male parent of FLBC2A, had eight F. pratensis-derived chromosomes and $20 \mathrm{~L}$. perennederived chromosomes (Fig. 2A), and 13EP4, the male parent of FLBC2C, had six $F$. pratensis-derived chromosomes and $20 \mathrm{~L}$. perenne-derived chromosomes (one of them display translocation from $F$. pratensis) (Fig. 2B). There might be more terminal translocations in both $\mathrm{BC}_{1}$ parents, but we could not confirm them clearly in this analysis. Segregation analysis identified 143 markers in FLBC2A and 126 markers in FLBC2C with dominant F. pratensis alleles, which were grouped in six of the expected seven LGs, with the exceptions of LG3 in FLBC2A and LG6 in FLBC2C (Table 6 Suppl.). In FLBC2A, several markers previously mapped on Festuca/Lolium LG3, including Festuca/Lolium intron-flanking markers corresponding to genes located on rice chromosome 1, showed the F. pratensis marker type in most $\mathrm{BC}_{2}$ individuals (data not shown), indicating that the extra chromosome detected by GISH was chromosome 3, corresponding to LG3. In FLBC2C, one additional LG composed of four markers was formed at LOD 9 but broke at LOD 10, set as the threshold in this study. This LG included Os02g57160, ACT-CTC 324, and ACC-CTA 285, mapped on LG6 in FLBC2A (Fig. 3), indicating that the partially recombined
F. pratensis-derived chromosome fragment originated from chromosome 6.

Significant distortion of segregation was seen on LG1 of both populations and on LG4 of FLBC2A(Table 6 Suppl.). In a comparison between maps, a significant difference in the $F$. pratensis-derived allele ratio at marker loci was seen only on LG1 $\left(\chi^{2}=7.2068, P=0.007\right.$; chi-squared test). The total length and mean intervals of the linkage maps were 301.2 and $2.2 \mathrm{cM}$ in FLBC2A and 256.2 and $2.1 \mathrm{cM}$ in FLBC2C (Table 6 Suppl.; Fig. 3). The two populations had 72 markers in common with a generally consistent genetic order (Fig. 3).

Interval mapping detected QTLs for seven of the nine traits in FLBC2A and for six traits in FLBC2C (Table 7 Suppl.; Fig. 3). QTLs for WHI with a positive effect of the $F$. pratensis allele were detected around markers NAF073 and NAF075 on LG1 in both FLBC2A (2015) and FLBC2C (2015 and 2016). In FLBC2A, other QTLs for WHI with a positive effect of the F. pratensis allele were detected on LG4 in 2014 and on LG5 in 2015, and one with a negative effect was detected on LG2 in 2015. A QTL for heading date was detected on LG7 in both populations, but only in one year each. QTLs for vigor index after planting and stubble width were detected on different LGs between FLBC2A and FLBC2C. QTLs for plant growth habit, inflorescence length, number of spikelets, leaf width, and dry matter before winter were detected in only one population.

\section{Discussion}

To construct linkage maps based on the segregation of

Fig. 3 (on the next page). Quantitative trait loci related to winter hardiness and other agronomic traits in the amphiploid Festulolium $\mathrm{BC}_{2}$ mapping populations FLBC2A $(A)$ and FLBC2C $(C)$. Vertical bars - 1.5-logarithm of odds (LOD) support intervals; $\triangle$ - first (solid line), second and third (broken line) LOD peaks. Diagonal lines connecting 72 common marker loci indicate a genetic linearity between the maps. DM - dry matter before winter; GH - plant growth habitat; HD - heading date; IL - inflorescence length; LW - leaf width; SN - number of spikelets per inflorescence; SW - stubble width; VI - vigor index after planting; WHI - winter hardiness index. Numbers 13 to 16 show years when the traits were evaluated (2013 to 2016). 


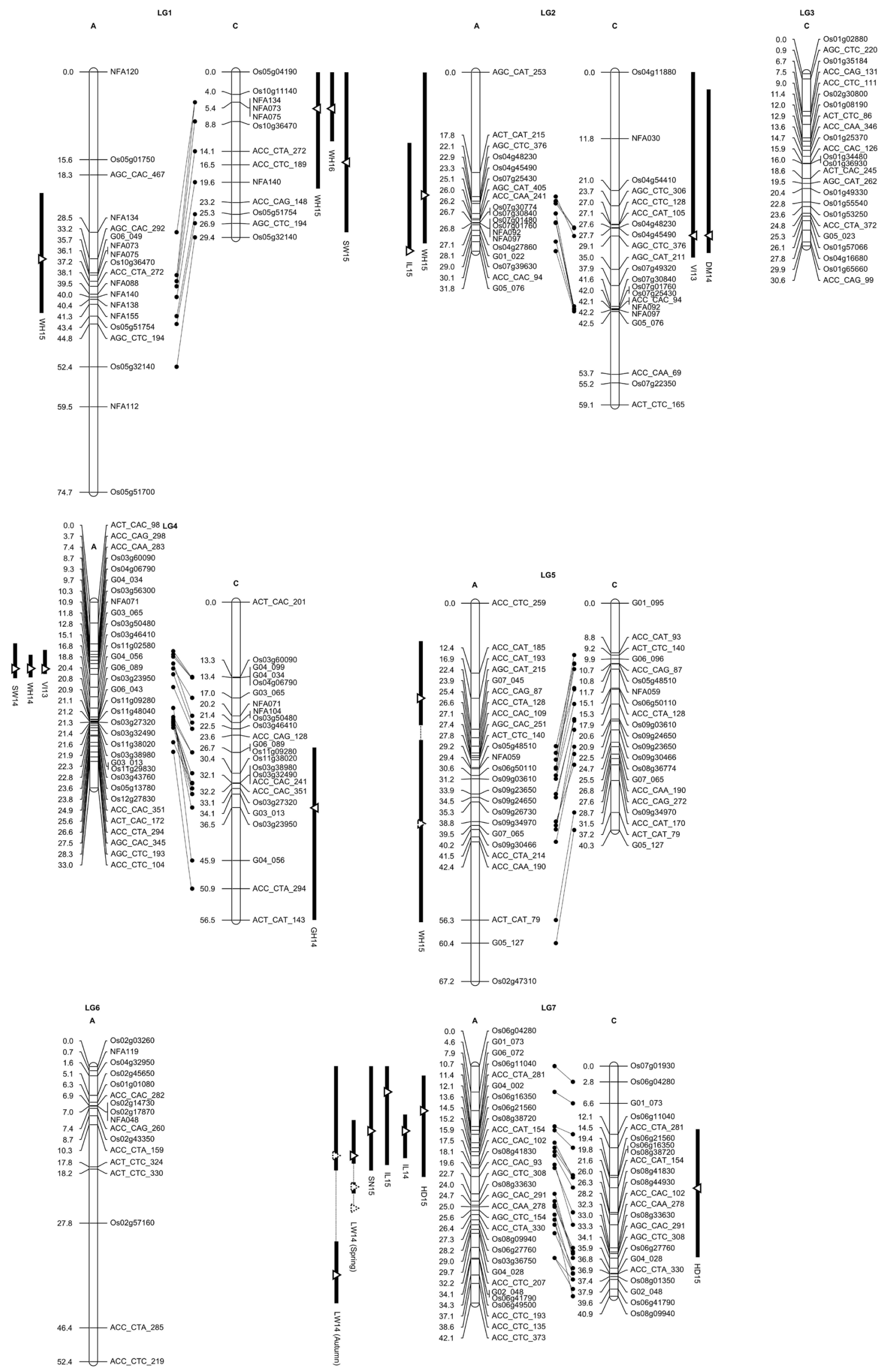


the presence/absence of $F$. pratensis-derived alleles, we generated two populations by two subsequent backcrosses of allotetraploid $F$. pratensis $\times$ L. perenne to autotetraploid L. perenne. $\mathrm{BC}_{1}$ parents used for the second backcross were disomic at $F$. pratensis chromosome 3 (FLBC2A) or had Lolium/Festuca chromosome rearrangement on chromosome 6 (FLBC2C), so each population had six out of the seven expected LGs, omitting LG3 in FLBC2A and LG6 in FLBC2C. If the $\mathrm{BC}_{1}$ parent had one complete set of $F$. pratensis chromosomes and three sets of $L$. perenne chromosomes without any homoeologous recombinations, seven LGs would be constructed in one segregating population. By combining the two populations, we could perform QTL analysis of the whole genome. Even allowing for the lack of one LG, the total map lengths of FLBC2C (301 cM) and FLBC2A (257 cM) were shorter than those of previous intraspecific genetic linkage maps: in L. perenne, $811 \mathrm{cM}$ of ILGI (Jones et al. 2002), $490.4 \mathrm{cM}$ of VrnA (Jensen et al. 2005), $628 \mathrm{cM}$ of F2/ WSC (Turner et al. 2006), and $804 \mathrm{cM}$ of Xtg-ART (Studer et al. 2006); and in F. pratensis, 581.5 and $602.3 \mathrm{cM}$ of B14/16xHF2 (Alm et al. 2003). Generally, a short map length is attributed to a low recombination frequency if enough markers are used. Although fewer markers were used to construct our maps than those mentioned above except for VrnA, we believe that our maps are adequately saturated since they are constructed mainly from intronflanking markers homologous to rice genes dispersed across the rice genome (Tamura et al. 2009). Moreover, all genetic distances between commonly mapped SSR markers on the same LG were shorter in our populations than in the L. perenne consensus linkage map (Studer et al. 2010; data not shown); e.g., genetic distances between G04 034 and G06 089 in LG4 were $10.7 \mathrm{cM}$ in FLBC2A and $\overline{1} 3.3 \mathrm{cM}$ in $\mathrm{FLBC} 2 \mathrm{C}$, but $59.9 \mathrm{cM}$ in the Lerenne map. Therefore, our results suggest that the frequency of homoeologous recombination between F. pratensis and L. perenne chromosomes is lower than that of homologous recombination in each species. Kopecký et al. (2008) reported that in monosomic introgression of individual $F$. pratensis chromosomes in an autotetraploid L. multiflorum background, the choice of a homologous or homoeologous partner at meiosis was completely random. On the other hand, $F$. pratensis monosomic introgression lines in a diploid $L$. perenne background had significantly fewer $L$. perenne/F. pratensis recombinant chromosomes than expected on the basis of chiasma frequency on chromosomes 2, 4, 5, and 6, although they had more on chromosome 1 (King et al. 2013). Therefore, in a tetraploid $L$. perenne background, some mechanism that reduces the frequency of homoeologous recombination might occur during meiosis. Significant segregation distortion was found in both populations along the entire LG1 with high frequency of $F$. pratensis-derived alleles. This phenomenon was reported in progeny of a triploid hybrid backcrossed to diploid L. perenne (King et al. 2013, Tamura et al. 2017), and so may be common in Lolium/ Festuca hybrids.

We observed large variations in WHI in the Festulolium $\mathrm{BC}_{2}$ populations, and identified QTLs for WHI on LGs
1, 2, 4, and 5. Except for QTLs on LG2 in FLBC2A, the direction of the effect of QTLs was positive when the allele were derived from $F$. pratensis, which has superior winter hardiness to L. perenne. QTLs on LG1 seem to be more reliable than the others because they were detected around common genetic markers in both populations. A QTL for WHI on LG4 detected after the first winter was located at the same maximum LOD position as the QTL for vigor index after planting before the first winter with positive effects of the $F$. pratensis allele. Thus, this locus might be only involved in vigor of the plants and the detection of the WHI QTL was affected by the vigor of the plants. Harper et al. (2018) reported that monosomic introgression of $F$. pratensis chromosome 4 into diploid L. perenne improved plant vigor (increased tiller number, shoot growth, and root growth), also supporting this hypothesis. QTLs on LG2 in FLBC2C for vigor after planting and dry matter before winter detected after the planting year seem also to be involved in plant vigor, with a positive effect of the L. perenne allele. The second LOD peak of the QTL for WHI on LG5 detected in FLBC2A was located near the intron-flanking EST marker position homologous to Os09g34970, which lies about $30 \mathrm{~kb}$ from the $C B F / D R E B$ gene cluster (OsDREB1A, OsDREB1B, $O S D R E B 1 H$ ) on rice chromosome 9 (Mao and Chen 2012). $C B F / D R E B$ genes encode the most important transcription unit involved in cold acclimatization in plants (Nakashima and Yamaguchi-Shinozaki 2006). In the Triticeae, a conserved QTL related to low-temperature tolerance, $F r$ 2 , assigned to the long arm of homoeologous group 5, was linked to the $C B F / D R E B$ gene cluster (Vágújfalvi et al. 2003, Francia et al. 2004, Miller et al. 2006, Tondelli et al. 2006). Zhu et al. (2014) and Würschum et al. (2017) reported that polymorphism or copy number variation of $C B F / D R E B$ genes at the $F r$ - $A 2$ locus is an essential component of freezing tolerance and winter survival in wheat. In $L$. perenne, a $C B F / D R E B$ gene cluster was identified in the syntenic genomic region on chromosome 5 (Tamura and Yamada 2007). In F. pratensis, QTLs for winter survival and freezing tolerance were found near the $C B F / D R E B$ locus (Alm et al. 2011). Although further detailed genetic mapping around this genomic region is required, these results suggest that $C B F / D R E B$ is a candidate locus responsible for the difference in winter hardiness between $F$. pratensis and L. perenne.

We also detected QTLs for other agronomic traits. Several studies reported heading-date QTLs on LG7 of L. perenne (Armstead 2004, 2005, Byrne et al. 2009), as we found in both populations here. Candidate genes for these QTLs include putative orthologs of genes for regulation of flowering time - LpFT3 $(H d 3)$ and $L p C O$ $(H d 1)$ - whose allelic variation contributes to variation in flowering time in L. perenne (Armstead et al. 2004, 2005, Martin et al. 2004, Skøt et al. 2011, Fé et al. 2015). From the collinearity between rice and Lolium/Festuca and the map positions of rice orthologous markers Os06g04280 and Os06g16350, the LOD peak of the QTL for heading date in FLBC2A seems to lie between the rice loci $\mathrm{Hd} 3$ (Os06g06320) and Hdl (Os06g16370), and that in FLBC2C seems to lie closer to $H d 1$ than to $H d 3$. Further 
detailed analysis using a candidate gene approach could clarify the genomic basis of these QTLs.

Festuca pratensis used in this study have wider leaves than the $L$. perenne (unpublished data). A QTL for leaf width was detected on LG7 in FLBC2A, with a positive effect of the $F$. pratensis allele. We could not judge whether this QTL has an additive effect due to the presence of an $F$. pratensis-derived genomic region or a dominant effect due to heterosis owing to the constitution of our mapping populations. Inflorescence (spike) length and spikelet number per inflorescence are important components of seed yield (Abel et al. 2017). Byrne et al. (2009) identified coincident QTLs for heading date, spike length, and spikelets per spike on LG4 in L. perenne. We found QTLs for inflorescence length and spikelet number per inflorescence near the QTL for heading date on LG7 in FLBC2A, suggesting a relationship between heading date and seed yield components.

The proportion of variance explained by the QTLs detected here ranged from 6.6 to $15.8 \%$, comparable to those in QTL analyses of intraspecific populations. We used linkage maps based on only the presence/absence of F. pratensis alleles, so QTLs derived from the variation in L. perenne alleles in the tetraploid background cannot be observed. Therefore, the total variance of QTLs in this study might be not as small as suggested. Despite the interspecies approach, however, the moderate QTL effects found here suggest a close evolutionary distance between the two species, as discussed by Harper et al. (2018), who did not find clear positive, negative, or even destructive effects of Festuca introgression in a genomewide sub-chromosomal introgression population except for the positive effect on plant vigor mentioned above. We detected many QTLs in only one population, although we have to take into account that the lower number of QTLs in FLBC2C when compared to FLBC2A may be due to the lower statistical power with a smaller population size ( $n=114$ in FLBC2C vs. $n=164$ in FLBC2A). Moreover, in genomic regions where $F$. pratensis introgression in L. perenne affected agronomic traits in previous studies, we did not necessarily detect QTLs; for example a QTL for winter hardiness with a positive effect of the $F$. pratensis region in L. perenne found on LG7 in the same nursery as in our study (Tamura et al. 2017) was not detected here. These suggest that these QTLs do not necessary determine phenotypic differences between the two species and are involved instead in intraspecies variation.

In conclusion, we identified QTLs associated with F. pratensis-derived genomic regions introduced into the tetraploid L. perenne background. QTLs depending on intraspecific variation or those with negative effects of F. pratensis introgression suggest that breeders should regard Festuca introgression into Lolium as the expansion of variation in the gene pool rather than as a unidirectional improvement in phenotypic performance. On the other hand, identification of QTLs with positive effects of $F$. pratensis alleles, especially commonly found in two different population such as those for winter hardiness, could lead to the development of markers with high versatility in Festulolium breeding.

\section{References}

Abel, S., Gislum, R., Boelt, B.: Path and correlation analysis of perennial ryegrass (Lolium perenne L.) seed yield components. - J. Agron. Crop Sci. 203: 338-344, 2017.

Akiyama, Y., Kubota, A., Yamada-Akiyama, H., Ueyama, Y.: Development of a genomic in situ hybridization (GISH) and image analysis method to determine the genomic constitution of festulolium $($ Festuca $\times$ Lolium $)$ hybrids. - Breed. Sci. 60: 347-352, 2010.

Alm, V., Busso, C.S., Ergon, A., Rudi, H., Larsen, A., Humphreys, M.W., Rognli, O.A.: QTL analyses and comparative genetic mapping of frost tolerance, winter survival and drought tolerance in meadow fescue (Festuca pratensis Huds.). Theor. appl. Genet. 123: 369-382, 2011.

Alm, V., Fang, C., Busso, C.S., Devos, K.M., Vollan, K., Grieg, Z., Rognli, O.A.: A linkage map of meadow fescue (Festuca pratensis Huds.) and comparative mapping with other Poaceae species. - Theor. appl. Genet. 108: 25-40, 2003.

Armstead, I.P., Turner, L.B., Farrell, M., Skøt, L., Gomez, P., Montoya, T., Donnison, I.S., King, I.P., Humphreys, M.O.: Synteny between a major heading-date QTL in perennial ryegrass (Lolium perenne $\mathrm{L}$.) and the $H d 3$ heading-date locus in rice. - Theor. appl. Genet. 108: 822-828, 2004.

Armstead, I.P., Skøt, L., Turner, L.B., Skøt, K., Donnison, I.S., Humphreys, M.O., King, I.P.: Identification of perennial ryegrass (Lolium perenne (L.)) and meadow fescue (Festuca pratensis (Huds.)) candidate orthologous sequences to the rice $\mathrm{Hd} 1(\mathrm{Sel})$ and barley $\mathrm{HvCO} 1 \mathrm{CONSTANS}$-like genes through comparative mapping and microsynteny. - New Phytol. 167: 239-247, 2005.

Byrne, S., Guiney, E., Barth, S., Donnison, I., Mur, L.A.J., Milbourne, D.: Identification of coincident QTL for days to heading, spike length and spikelets per spike in Lolium perenne L. - Euphytica 166: 61-70, 2009.

Byrne, S.L., Nagy, I., Pfeifer, M., Armstead, I., Swain, S., Studer, B., Mayer, K., Campbell, J.D., Czaban, A., Hentrup, S., Panitz, F., Bendixen, C., Hedegaard, J., Caccamo, M., Asp, T.: A synteny-based draft genome sequence of the forage grass Lolium perenne. - Plant J. 84: 816-826, 2015.

Fé, D., Cericola, F., Byrne, S., Lenk, I., Ashraf, B.H., Pedersen, M.G., Roulund, N., Asp, T., Janss, L., Jensen, C.S., Jensen, J.: Genomic dissection and prediction of heading date in perennial ryegrass. - BMC Genomics 16: 921, 2015.

Francia, E., Rizza, F., Cattivelli, L., Stanca, A.M., Galiba, G., Tóth, B., Hayes, P.M., Skinner, J.S., Pecchioni, N.: Two loci on chromosome $5 \mathrm{H}$ determine low-temperature tolerance in a 'Nure' (winter) $\times$ 'Tremois' (spring) barley map. - Theor. appl. Genet. 108: 670-680, 2004.

Ghesquière, M., Humphreys, M.W., Zwierzykowski, Z.: Festulolium. - In: Boller, B., Posselt, U.K., Veronesi, F. (ed.): Fodder Crops and Amenity Grasses. Handbook of Plant Breeding 5. Pp. 293-316. Springer, Dordrecht 2010.

Grønnerød, S., Fjellheim, S., Humphreys, M.W., Østrem, L., Canter, P.H., Grieg, Z., Jørgensen, Ø., Larsen, A., Rognli, O.A.: Application of AFLP and GISH techniques for identification of Festuca chromosome segments conferring winter hardiness in a Lolium perenne $\times$ Festuca pratensis population. - In: Wang, Z.Y., Mian, R., Sledge, M., Baker, R.E. (ed.): Molecular Breeding of Forage and Turf. Pp 81-86. Kluwer Academic Publishers, Dordrecht 2004.

Harper, J., Gasior, D., Mathews, R., Thomas, A., Evans, C., King, J., King, I., Humphreys, M., Armstead, I.: An investigation of genotype-phenotype association in a Festulolium forage grass population containing genome-spanning Festuca pratensis chromosome segments in a Lolium perenne background. - 
PLoS ONE 13: e0207412, 2018.

Humphreys, M.W., Gasior, D., Lesniewska-Bocianowska, A., Zwierzykowski, Z., Rapacz, M.: Androgenesis as a means of dissecting complex genetic and physiological controls: selecting useful gene combinations for breeding freezing tolerant grasses. - Euphytica 158: 337-345, 2007.

Jensen, L.B., Andersen, J.R., Frei, U., Xing, Y.Z., Taylor, C., Holm, P.B., Lubberstedt, T.L.: QTL mapping of vernalization response in perennial ryegrass (Lolium perenne L.) reveals co-location with an orthologue of wheat VRN1. - Theor. appl. Genet. 110: 527-536, 2005.

Jones, E.S., Mahoney, N.L., Hayward, M.D., Armstead, I.P., Jones, J.G., Humphreys, M.O., King, I.P., Kishida, T., Yamada, T., Balfourier, F., Charmet, G., Forster, J.W.: An enhanced molecular marker based genetic map of perennial ryegrass (Lolium perenne) reveals comparative relationships with other Poaceae genomes. - Genome 45: 282-295, 2002.

King, J., Armstead, I., Harper, J., King, I.: Transmission frequencies of introgressed Festuca pratensis chromosomes and chromosome segments in Lolium perenne. - Crop Sci. 53: 1968-1973, 2013.

Kopecký, D., Lukaszewski, A.J., Doležel, J.: Meiotic behaviour of individual chromosomes of Festuca pratensis in tetraploid Lolium multiflorum. - Chromosome Res. 16: 987-998, 2008.

Kopecký, D., Havránková, M., Loureiro, J., Castro, S., Lukaszewski, A.J., Bartoš, J., Kopecká, J., Doležel, J.: Physical distribution of homoeologous recombination in individual chromosomes of Festuca pratensis in Lolium multiflorum. - Cytogenet. Genome Res. 129: 162-172, 2010.

Kosmala, A., Zwierzykowski, Z., Gasior, D., Rapacz, M., Zwierzykowska, E., Humphreys, M.W.: GISH/FISH mapping of genes for freezing tolerance transferred from Festuca pratensis to Lolium multiflorum. - Heredity 96: 243-251, 2006.

Kosmala, A., Zwierzykowski, Z., Zwierzykowska, E., Luczak, M., Rapacz, M., Gasior, D., Humphreys, M.W.: Introgression mapping of genes for winter hardiness and frost tolerance transferred from Festuca arundinacea into Lolium multiflorum. - J. Hered. 98: 311-316, 2007.

Majka, J., Bzdęga, K., Janiak, A., Ćwiek-Kupczyńska, H., Krajewski, P., Książczyk, T., Zwierzykowski, Z.: Cytogenetic and molecular genotyping in the allotetraploid Festuca pratensis $\times$ Lolium perenne hybrids. - BMC Genomics $\mathbf{2 0}$ : 367, 2019.

Mao, D.H., Chen, C.Y.: Colinearity and similar expression pattern of rice DREB1s reveal their functional conservation in the cold-responsive pathway. - PLoS ONE 7: e47275, 2012.

Martin, J., Storgaard, M., Andersen, C.H., Nielsen, K.K.: Photoperiodic regulation of flowering in perennial ryegrass involving a CONSTANS-like homolog. - Plant mol. Biol. 56: $159-169,2004$

Miller, A.K., Galiba, G., Dubcovsky, J.: A cluster of $11 C B F$ transcription factors is located at the frost tolerance locus $\mathrm{Fr}$ A(m) 2 in Triticum monococcum. - Mol. Genet. Genomics 275: 193-203, 2006.

Nakashima, K., Yamaguchi-Shinozaki, K.: Regulons involved in osmotic stress-responsive and cold stress-responsive gene expression in plants. - Physiol. Plant 126: 62-71, 2006.

Saha, M.C., Mian, M.A.R., Eujayl, I., Zwonitzer, J.C., Wang, L.J., May, G.D.: Tall fescue EST-SSR markers with transferability across several grass species. - Theor. appl. Genet. 109: 783791, 2004.

Skøt, L., Sanderson, R., Thomas, A., Skøt, K., Thorogood, D., Latypova, G., Asp, T., Armstead, I.: Allelic variation in the perennial ryegrass FLOWERING LOCUS T gene is associated with changes in flowering time across a range of populations.
- Plant Physiol. 155: 1013-1022, 2011.

Studer, B., Boller, B., Herrmann, D., Bauer, E., Posselt, U.K., Widmer, F., Kölliker, R.: Genetic mapping reveals a single major QTL for bacterial wilt resistance in Italian ryegrass (Lolium multiflorum Lam.). - Theor. appl. Genet. 113: 661671, 2006.

Studer, B., Kölliker, R., Muylle, H., Asp, T., Frei, U., RoldánRuiz, I., Barre, P., Tomaszewski, C., Meally, H., Barth, S., Skøt, L., Armstead, I.P., Dolstra, O., Lübberstedt, T.: ESTderived SSR markers used as anchor loci for the construction of a consensus linkage map in ryegrass (Lolium spp.). - BMC Plant Biol. 10: 177, 2010.

Tamura, K., Kiyoshi, T., Yonemaru, J.: The development of highly transferable intron-spanning markers for temperate forage grasses. - Mol. Breed. 30: 1-8, 2012.

Tamura, K., Tase, K., Sanada, Y., Komatsu, T., Yonemaru, J., Kubota, A.: Effects of introgressions from Festuca pratensis on winter hardiness of Lolium perenne. - Euphytica 213: 226, 2017.

Tamura, K., Yamada, T.: A perennial ryegrass $C B F$ gene cluster is located in a region predicted by conserved synteny between Poaceae species. - Theor. appl. Genet. 114: 273-283, 2007.

Tamura, K., Yonemaru, J., Hisano, H., Kanamori, H., King, J., King, I.P., Tase, K., Sanada, Y., Komatsu, T., Yamada, T.: Development of intron-flanking EST markers for the Lolium/ Festuca complex using rice genomic information. - Theor. appl. Genet. 118: 1549-1560, 2009.

Tondelli, A., Francia, E., Barabaschi, D., Aprile, A., Skinner, J.S., Stockinger, E.J., Stanca, A.M., Pecchioni, N.: Mapping regulatory genes as candidates for cold and drought stress tolerance in barley. - Theor. appl. Genet. 112: 445-454, 2006.

Turner, L.B., Cairns, A.J., Armstead, I.P., Ashton, J., Skøt, K., Whittaker, D., Humphreys, M.O.: Dissecting the regulation of fructan metabolism in perennial ryegrass (Lolium perenne) with quantitative trait locus mapping. - New Phytol. 169: 4557, 2006.

Vágújfalvi, A., Galiba, G., Cattivelli, L., Dubcovsky, J.: The cold-regulated transcriptional activator $C b f 3$ is linked to the frost-tolerance locus Fr-A2 on wheat chromosome 5A. - Mol. Genet. Genomics 269: 60-67, 2003.

Van Ooijen, J.W.: JoinMap 4, Software for the Calculation of Genetic Linkage Maps in Experimental Populations. Kyazma B.V., Wageningen 2006.

Van Ooijen, J.W.: MapQTL 6, Software for the Mapping of Quantitative Trait Loci in Experimental Populations of Diploid Species. - Kyazma B.V, Wageningen 2009.

Würschum, T., Longin, C.F.H., Hahn, V., Tucker, M.R., Leiser, W.L.: Copy number variations of $C B F$ genes at the $F r-A 2$ locus are essential components of winter hardiness in wheat. Plant J. 89: 764-773, 2017.

Yamada, T., Jones, E.S., Cogan, N.O.I., Vecchies, A.C., Nomura, T., Hisano, H., Shimamoto, Y., Smith, K.F., Hayward, M.D., Forster, J.W.: QTL analysis of morphological, developmental, and winter hardiness-associated traits in perennial ryegrass. Crop Sci. 44: 925-935, 2004.

Zhu, J., Pearce, S., Burke, A., See, D.R., Skinner, D.Z., Dubcovsky, J., Garland-Campbell, K.: Copy number and haplotype variation at the $V R N-A 1$ and central $F R-A 2$ loci are associated with frost tolerance in hexaploid wheat. - Theor. appl. Genet. 127: 1183-1197, 2014.

Zwierzykowski, Z., Zwierzykowska, E., Taciak, M., Jones, N., Kosmala, A., Krajewski, P.: Chromosome pairing in allotetraploid hybrids of Festuca pratensis $\times$ Lolium perenne revealed by genomic in situ hybridization (GISH). Chromosome Res. 16: 575-585, 2008. 